\title{
Teoría y elección metodológica en la investigación
}

\author{
Carles Roca-Cuberes \\ Universitat Pompeu Fabra \\ carles.roca@upf.edu \\ ORCID: 0000-0002-6201-0680
}

DOI: 10.31009/methodos.2020.i01.01

Roca-Cuberes, C. (2020). Teoría y elección metodológica en la investigación. En: Lopezosa, C.; Díaz-Noci, J.; Codina, L. (ed.). Anuario de Métodos de Investigación en Comunicación Social, n.1 (p.01-03). Barcelona: DigiDoc-Universitat Pompeu Fabra

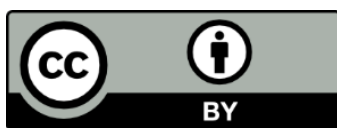





\title{
Teoría y elección metodológica en la investigación
}

\author{
Carles Roca-Cuberes \\ Universitat Pompeu Fabra \\ carles.roca@upf.edu \\ ORCID: 0000-0002-6201-0680
}

\section{La teoría en las ciencias sociales}

$\mathrm{u}$ otorgarle un valor que trascienda y desborde los marcos de un contexto espacio-temporal concreto.

Según Kaplan, la teoría representa la dimensión simbólica de la experiencia, en oposición a la aprehensión del hecho en bruto. Para él, comprometerse a teorizar significa no sólo aprehender mediante la experiencia, sino tomar conciencia de lo aprehensible (Kaplan, 2017).

La teoría representa el fin de la labor científica y su última sistematización. Cada teoría tiene una estructura compleja, y la forma en que esta estructura está construida se encuentra directamente relacionada con las concepciones epistemológicas del científico, con su concepción del mundo, con determinados principios metodológicos sobre cómo enfocar el escrutinio de la realidad. Todas las teorías (tanto las naturales como las sociales) son suscitadas por las condiciones históricas en las que surgen, por las normas sociales imperantes en su momento, etc. En definitiva, todas las teorías científicas no dejan de ser el producto de un contexto histórico y espacial determinados. Y esto tiene que ver con la cuestión de la validez y el alcance de una teoría social, y contradice la supuesta visión de la ciencia como a-ideológica, a-política, a-valorativa, y con la asignación de un carácter universal y objetivo de las teorías. Así pues, si la teoría es una respuesta y proyección de una praxis en un contexto y en una circunstancia histórica bien determinada, resulta erróneo asignarle una universalidad absoluta

\section{Principales paradigmas - familias teóricas en las ciencias sociales a teoría en las ciencias sociales}

En las ciencias sociales podemos encontrar tres grandes familias teóricas o paradigmas: paradigma positivista, paradigma interpretativo y paradigma sociocrítico (Guba \& Lincoln, 1994). Podemos afirmar que las diferentes perspectivas teóricas que se agrupan en estas tres grandes familias lo hacen por que comparten una serie de principios. Al mismo tiempo, un paradigma suele englobar varias perspectivas teórico-metodológicas, y además se caracteriza por una serie de principios o supuestos generales (ontológicos, epistemológicos, metodológicos). Las perspectivas se podrían denominar paradigmas de rango inferior o 'miniparadigmas'.

Los paradigmas deben entenderse como sistemas de creencias básicas (principios, supuestos) sobre: (1) la naturaleza de la realidad investigada (principio ontológico); (2) la naturaleza del conocimiento que el investigador produce, basado en el modelo de relación entre el investigador y lo investigado (principio

DOI: 10.31009/methodos.2020.i01.01 
epistemológico); (3) como accedemos al conocimiento de la realidad (principio metodológico).

Estos tres niveles están interrelacionados verticalmente, de forma que cualquier creencia básica o principio que asuma el investigador al nivel ontológico debería llevar a adoptar posturas consonantes en los niveles epistemológico y metodológico.

\section{Paradigma positivista}

El origen del paradigma positivista lo encontramos en August Comte. Aunque fue él el primero en utilizar la palabra 'sociología', a esta nueva ciencia la quería denominar 'física social'. Esta nueva ciencia debía proceder según unos principios comunes al conjunto de las ciencias: (1) monismo metodológico (unidad del método científico con independencia de los objetos temáticos de la investigación); (2) las ciencias naturales exactas establecen un canon o ideal metodológico que mide el grado de desarrollo y perfección de todas las demás ciencias, incluidas las humanidades; (3) La explicación científica nos debe servir fundamentalmente para predecir, prever, mediante explicación causal (Comte, 1851).

El positivismo constituye un intento de traslado de la forma en que se estudian los objetos de la naturaleza a las ciencias sociales. El modelo a seguir es la física. Los principales preceptos generales son: (1) el fenómeno que se quiere estudiar es uno, tangible y fragmentable, y hay una única y mejor forma de describir cualquier aspecto de ese fenómeno. (2) El investigador y su objeto de investigación son independientes. (3) El resultado de la investigación son generalizaciones en forma de 'leyes', que son independientes del tiempo y del contexto. (4) Los conceptos científicos son precisos y tienen significados fijos e invariables. (5) La explicación de fenómenos toma la forma de explicaciones causa-efecto; estas relaciones causa-siguen una lógica de investigación hipotético-deductiva. (6) La investigación es objetiva y, por tanto, libre de valores.

Algunas de las perspectivas teóricas o miniparadigmas más importantes en esta tradición son el funcionalismo (sociología) y el conductismo (psicología), aunque la influencia de este paradigma ha permeado al conjunto de las ciencias sociales.

\section{Paradigma interpretativo}

Originado en el trabajo de los sociólogos alemanes Max Weber y Georg Simmel, desde este paradigma se asume que la gente crea y asocia sus propios significados subjetivos e intersubjetivos a medida que interactúa con el mundo que le rodea. En este sentido, los investigadores deben intentar comprender la realidad a través del estudio de los significados que la gente asigna a esta realidad. En contraposición al positivismo, no se cree en una realidad objetiva e independiente del investigador y, en consecuencia, el estudio que se haga de la realidad tampoco podrá ser objetivo. Se tienden a hacer micro-estudios de grupos, colectivos o lugares y, en consecuencia, no se busca la generalización. Se persigue una profundización en la comprensión de fenómenos en su contexto cultural y temporal; los fenómenos se estudian en el lugar donde se producen, se adopta la perspectiva de aquellos que los generan y no la del investigador y sus teorías. De esta manera, se entiende que la realidad y el conocimiento que podemos generar de ella, son productos sociales: no se pueden entender con independencia de los actores sociales (incluidos los investigadores) que construyen y otorgan sentido a esta realidad. En definitiva, desde el paradigma interpretativo se asume que el mundo (social) no es una realidad objetiva, sino un proceso social. El objetivo de la investigación de carácter interpretativo es comprender como los miembros de un determinado grupo social, a través de su participación en los procesos sociales, crean su particular realidad y le otorgan significados, y mostrar cómo estos significados, creencias, intenciones, etc., les permiten llevar a cabo la acción social. Desde este paradigma se busca comprender los significados intersubjetivos adscritos a la vida social y explicar cómo la gente actúa de la forma que lo hace.

Las perspectivas teóricas más importantes en este paradigma son el interaccionismo simbólico y la etnometodología.

\section{Paradigma sociocrítico}

Lo que distingue al paradigma sociocrítico, basado en la sociología de Karl Marx, es su dimensión evaluativa. El investigador social crítico intenta evaluar críticamente y transformar la realidad que investiga. Se busca criticar el statu quo, a través de exponer las profundas contradicciones estructurales propias del sistema social, y a través de esta crítica transformar estas condiciones que son restrictivas y alienantes. Todo esto se hace a través de un análisis de tipo dialéctico que intenta revelar la naturaleza histórica, ideológica y contradictoria de determinadas prácticas sociales. Las perspectivas teóricas más conocidas dentro de este paradigma son la Teoría Crítica y los Estudios Culturales Británicos. 


\section{Comparación entre paradigmas}

\begin{tabular}{|c|c|c|c|}
\hline \multicolumn{4}{|c|}{ COMPARACIÓN ENTRE PARADIGMAS } \\
\hline $\begin{array}{l}\text { Creencias básicas/ } \\
\text { Paradigma }\end{array}$ & Positivista & Interpretativo & Sociocrítico \\
\hline $\begin{array}{l}\text { Ontología. Naturaleza de la } \\
\text { realidad }\end{array}$ & $\begin{array}{l}\text { Una realidad conocible } \\
\text { con probabilidad }\end{array}$ & $\begin{array}{l}\text { Múltiple, sociabilidad, } \\
\text { realidades construidas }\end{array}$ & $\begin{array}{c}\text { Realidades múltiples compartidas } \\
\text { por valores sociales, políticos, } \\
\text { culturales, económicos, étnicos y } \\
\text { de género }\end{array}$ \\
\hline $\begin{array}{l}\text { Epistemología. Naturaleza } \\
\text { del conocimiento, relación } \\
\text { entre lo conocido y lo que } \\
\text { puede ser conocido }\end{array}$ & $\begin{array}{l}\text { Objetividad, } \\
\text { investigación manipu- } \\
\text { lativa y observación } \\
\text { desapasionada }\end{array}$ & $\begin{array}{l}\text { Enlace interactivo entre } \\
\text { investigadores y partici- } \\
\text { pantes, valores explícitos, } \\
\text { hallazgos creados }\end{array}$ & $\begin{array}{l}\text { Conocimiento situado en un } \\
\text { contexto social e histórico }\end{array}$ \\
\hline $\begin{array}{l}\text { Metodología o acceso al } \\
\text { conocimiento }\end{array}$ & $\begin{array}{l}\text { Principalmente cuanti- } \\
\text { tativo, intervencionista, } \\
\text { descontextualizado }\end{array}$ & $\begin{array}{l}\text { Principalmente cualitativo, } \\
\text { los factores son descritos } \\
\text { en forma dialéctica, } \\
\text { hermenéutica y contextual }\end{array}$ & $\begin{array}{l}\text { Más énfasis en lo cualitativo } \\
\text { (dialogante), puede usarse el } \\
\text { diseño cuantitativo, factores } \\
\text { contextuales e históricos relacio- } \\
\text { nados con la opresión }\end{array}$ \\
\hline
\end{tabular}

Tabla 1. Comparación entre paradigmas. Fuente: Mertens 1998.

\section{Consideraciones importantes en el momento de elegir la metodología en una investigación eóricas en las ciencias sociales}

La interrelación vertical entre los principios (ontológico, epistemológico y metodológico) que permiten clasificar a los paradigmas nos conducen a algunas consideraciones sobre cómo debe proceder el investigador en el momento de elegir la metodología para su investigación. Tal y como hemos visto antes, las decisiones de tipo metodológico son transcendidas por las creencias de tipo ontológico y metodológico. Esto implica que antes de decidir el/los método/s de investigación, el investigador debe resolver con qué visión ontológica y epistemológica de los tres paradigmas se siente más identificado; en función de esto, deberá elegir el método correspondiente. Por ejemplo, si el investigador considera que la realidad está socialmente construida, no tendría mucho sentido que usara metodologías de tipo cuantitativo. Si el investigador opta por la triangulación metodológica, tampoco parecería muy coherente combinar métodos cuantitativos y cualitativos en una misma investigación, puesto que (implícitamente) estaría apuntando a creencias ontológicas y epistemológicas de signo diferente o incluso opuesto.

\section{Bibliografía}

Comte, A. (1851). General view of positivism. New York: R. Speller.

Guba, E. G. \& Lincoln, Y. S. (1994). Effective evaluation. San Francisco: Jossey-Bass.

Kaplan, A. (2017). The conduct of inquiry: Methodology for behavioural science. London: Routledge.

Mertens, D. M. (1988). Research methods in Education and Psychology. Thousand Oaks (USA): Sage. 


ISBN 978-84-09-20524-0

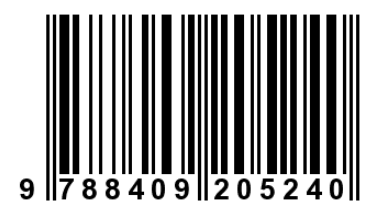

Máster Universitario en Investigación en Comunicación Social (MUCS)

\begin{tabular}{l|ll}
$\mathbf{u} p f$. & $\begin{array}{l}\text { Universitat } \\
\text { Pompeu Fabra } \\
\text { Barcelona }\end{array}$ & $\begin{array}{l}\text { DIGIDOC Grup de Recerca } \\
\text { en Documentació Digital } \\
\text { i Comunicació Interactiva }\end{array}$
\end{tabular} 